\title{
Oral administration of Grifola frondosa affect lipid metabolism and insulin signaling pathway on BKS. Cg-+Lepr ${ }^{\mathrm{db}} /+$ Lepr $^{\mathrm{db}} /$ OlaHsd mouse
}

\author{
Seong-Bo Yun and Dae-Young Kim* \\ Department of Life Science, College of Bio-Nano Technology, Gachon University, Seongnam 13120, Korea
}

Received November 9, 2021

Revised November 19, 2021

Accepted November 22, 2021

*Correspondence

Dae-Young Kim

E-mail: davekim@gachon.ac.kr

Author's Position and Orcid no.

Yun SB, MS student,

https://orcid.org/0000-0003-0068-0694

Kim DY, Professor,

https://orcid.org/0000-0003-1608-8441

\begin{abstract}
Diabetic mellitus (DM) is a carbohydrate metabolic disorder that involves high blood sugar because insulin works abnormally. Type 2 diabetes accounts for most of them. However, diabetes treatments such as GLP-1 and DPP-4 inhibitors commonly caused side effects including gastrointestinal disorders. Grifola frondosa ( $G$. frondosa) revealed various pharmacological effects in recent studies. It has a variety of anti-cancer polysaccharides through host-mediated mechanisms. D-fraction in G. frondosa has apoptotic effects, promoting myeloid cell proliferation and differentiation into granulocytes-macrophages. It has also been shown to reduce the survival rate of breast cancer cells. Though, no further study has been conducted on the specific effects of $\mathrm{G}$. frondosa in the $\mathrm{db} / \mathrm{db}$ mouse. Therefore, we would like to research the blood glucose improving effect of $G$. frondosa, a natural material, in type 2 diabetes model mouse, in this study. G. frondosa was administered to the disease model mouse (BKS.Cg-+Lepr $^{\mathrm{db}} /+$ Lepr $^{\mathrm{db}} / \mathrm{OlaHsd}$ ) for 8 weeks to monitor weight and blood glucose changes every week. And we evaluated anti-diabetes effects by checking biomarker changes shown through blood. Experiment did not show statistically significant weight differences, but control groups showed significantly higher weight gain than G. frondosa administered groups. We collected blood from the tail veins of the $\mathrm{db} / \mathrm{db}$ mouse each week. As a result, the lowest blood sugar level was shown in the $500 \mathrm{mg} /$ $\mathrm{kg}$ group of $\mathrm{G}$. frondosa. Glucose in the blood was examined with HBA1c, and $7.8 \%$ was shown in the $500 \mathrm{mg} / \mathrm{kg}$ administration group, lower than in other groups. These results suggest the potential improvements of diabetes in $G$. frondosa.
\end{abstract}

Keywords: db/db mouse, diabetic mellitus, Grifola frondosa, type 2 diabetes

\section{INTRODUCTION}

Diabetes mellitus is a carbohydrate metabolism disorder accompanied by hyperglycemia occurring when the rate of insulin secretion is insufficient because insulin synthesis is hindered or when normal functions of insulin are not carried out in the liver, fat, and muscle tissues due to insulin resistance (Park et al., 2007; Joung et al.,
2017). Type 2 diabetes accounts for most of the diabetes, and South Korea is no exception. According to the International Diabetes Federation (IDF), the prevalence rates of diabetes and impaired glucose tolerance (IGT) among adults aged 20-79 years in South Korea as of 2017 were 8.84 and $13.76 \%$, respectively, and were predicted to increase to 12.08 and $16 \%$, respectively, by 2045 , and the global prevalence rates were predicted to increase by $48 \%$ 
(International Diabetes Federation, 2015).

BKS.Cg-+Lepr ${ }^{\mathrm{db}} /+$ Lepr $^{\mathrm{db}} /$ OlaHsd mice, which are used as animal models for type 2 diabetes, develop symptoms of diabetes by themselves due to the genetic variation occurred in their leptin receptors. They are also called $\mathrm{db} /$ $\mathrm{db}$ mice because of the genetic variation occurred in their $\mathrm{db}$ genes. In this animal model, the response to the leptin receptors is lost so that obesity is developed from four weeks after birth leading to the occurrence of hyperglycemia under which the blood sugar concentration is maintained at least at $300 \mathrm{mg} / \mathrm{dL}$ from the 5 th week. On the other hand, as the responsiveness to insulin decreases, the insulin concentration is maintained high (Kanasaki et al., 2011).

The most common side effects of GLP-1 analogues as remedial agents for diabetes are gastrointestinal disturbances and nausea. These side effects are dose-dependent (Reid, 2013). In addition, in the case of DPP-4 inhibitors, the most common reported side effect is gastrointestinal disturbances (Yang et al., 2016). DPP-4 inhibitors also increased the risk of pancreatitis and pancreatic cancer (Nagel et al., 2016).

G. frondosa has been used as food for a long time, mainly in Japan. It looks like many folds of ginkgo leaves and its color is black, brown, or white. Recent studies show various pharmacological actions of $G$. frondosa. Anticancer activity is representative, and it has various anticancer polysaccharides that act on cancer cells through a host-mediated mechanism rather than directly acting on cancer cells. The polysaccharide called GF-1 has anticancer effects like those of lentinan of 6 -branced $\beta-1,3-$ glucan (Suzuki et al., 1984). In addition, the D-fraction present in $G$. frondosa strengthens the immune system. Furthermore, D-fraction is known to exhibit apoptotic effect, promote the proliferation of bone marrow cells and differentiation into granulocytes-macrophages, and reduce the survival rate of breast cancer cells (Soares et al., 2011). In addition, a blood sugar lowering effect of D-fraction is known. It was found that D-fraction lowers blood sugar levels with its inhibitory effect on $\alpha$-glucosidase (Matsuura et al., 2002; Xiao et al., 2011).

It was reported through an experiment with KK-Ay mice that the antidiabetic activity of $\alpha$-glucan of $G$. frondosa improves insulin sensitivity at insulin receptors and insulin resistance of peripheral target tissues. The polysaccharide of $G$. frondosa helps glucose absorption in
HepG2 cells, activates the insulin receptor protein in cell membranes, and increase the phosphorylated AktSer473 production, thereby stabilizing insulin resistance (Ma et al., 2014). However, the concrete effect of $G$. frondosa in $\mathrm{db} / \mathrm{db}$ mice has not been studied thus far.

In this study, to see the blood sugar enhancing effect of $G$. frondosa, a natural material, in type 2 diabetes model mice, type 2 diabetes developing mouse (BKS.Cg+ Lepr $^{\mathrm{db}} /+$ Lepr $^{\mathrm{db}} / \mathrm{OlaHsd}$ ) were fed $G$. frondosa for 8 weeks to observe changes in body weight and blood glucose every week. The effect of reducing blood sugar was evaluated by checking the variances of lipid biochemical indicators and biomarkers that appeared through blood.

\section{MATERIALS AND METHODS}

\section{Animal model and experimental design}

Five-weeks-old BKS.Cg-+Lepr ${ }^{\mathrm{db}} /+$ Lepr $^{\mathrm{db}} /$ OlaHsd mice (n = 20) were purchased from Doo Yeol Bio (Osan, Korea), and after having an adaptation period of about 16 days. Mouse was accommodated in a plastic mouse cage, and the breeding environment in the room was adjusted from $23^{\circ} \mathrm{C}$ to $27^{\circ} \mathrm{C}$, humidity was $50-60 \%$, and photoperiod was adjusted for 12 hours. The mouse was randomly selected and divide into four groups each. The experimental groups are as shown in Table 1.

G. frondosa (in the form of feed) was provided from Hyunsol, an agricultural corporation (Incheon, Korea), and stored at $4{ }^{\circ} \mathrm{C}$. In this study, it was fed for 8 weeks. $G$. frondosa was provided in the form of feed (Doo Yeol Bio, Korea) with $0 \mathrm{mg} / \mathrm{kg}$ (control), $100 \mathrm{mg} / \mathrm{kg}, 200 \mathrm{mg} / \mathrm{kg}$, and $500 \mathrm{mg} / \mathrm{kg}$.

The amount of feed, water, and blood sugar were checked per a week and the body weight was measured. Blood sugar was measured by tail, and if blood was collected from veins and more than $601 \mathrm{mg} / \mathrm{dL}$, accurate

Table 1. Experiment group

\begin{tabular}{cl}
\hline \multicolumn{1}{c}{ Group } & \multicolumn{1}{c}{ Feeding } \\
\hline A (control) & G. frondosa $0 \mathrm{mg} / \mathrm{kg}$ \\
B & G. frondosa $100 \mathrm{mg} / \mathrm{kg}$ \\
C & G. frondosa $200 \mathrm{mg} / \mathrm{kg}$ \\
D & G. frondosa $500 \mathrm{mg} / \mathrm{kg}$ \\
\hline
\end{tabular}

The intake is as shown in the table above. The concentration $(0 \mathrm{mg} / \mathrm{kg}$, $100 \mathrm{mg} / \mathrm{kg}, 200 \mathrm{mg} / \mathrm{kg}, 500 \mathrm{mg} / \mathrm{kg}$ ) was different for each group and intake. 
blood sugar measurement was not possible, so the result data was processed assuming $601 \mathrm{mg} / \mathrm{dL}$.

The experimental animals were observed to see whether there were any individuals exhibiting abnormalities such as rapid weight gain, wounds, and abnormal hair conditions. This experiment was conducted in accordance with the guidelines on the management and use of experimental animals with the approval of the Institutional Animal Care and Use Committee of Gachon University (Permit Number: GIACUC-R2017033).

\section{Autopsy and blood collection}

At the end of the experiment for eight weeks, the animals were fasted for 12 hours, deeply anesthetized with inhalation anesthesia, and euthanized. The animals were anesthetized by isoflurane inhalation in an enclosed chamber (Cho et al., 2020).

After skin incision was performed, the abdominal vena cava was found through the abdominal cavity, and a 23G needle $2 \mathrm{~mL}$ was inserted into it to collect blood maximally before blood coagulation was shown.

When blood was collected, about $1 \mathrm{~mL}$ of the blood was put into a CBC bottle (SEWON MEDICAL) containing the anticoagulant $\mathrm{K}_{2}$ EDTA for whole blood testing, and all the remaining blood was placed in a BD Vacutainer ${ }^{\circledR}$ Blood collection tube (BD367953, BD, NJ, USA) and stored in an ice bucket. The blood was centrifuged for 15 minutes at $3,000 \mathrm{rpm}$, and only the serum was separated and stored at $-85^{\circ} \mathrm{C}$.

For additional molecular biological tests, a part of each organ (liver, pancreas, kidney) was put into an e-tube and chopped, and thereafter mixed with RAN later ${ }^{\circledR}$ (AM7021, Thermo fisher) and stored at $-80^{\circ} \mathrm{C}$.

Each important organ was visually evaluated, and the weighs of the brain, heart, liver, pancreas, spleen, kidney, etc. were measured and recorded to 4 decimal places using a micro scale. Each organ was immersed in a fixative such as neutral formalin and stored for histopathological analysis.

\section{Blood biochemical test}

Blood biochemical tests were performed using Accute TBA-40FR (Toshiba Medical Systems Co., Japan) to analyze a total of four items: triglycerides $(\mathrm{mg} / \mathrm{dL})$, cholesterol (mg/dL), HDL (mg/dL), and LDL (mg/dL).

\section{Measurement of HbA1c}

After blood collection, some immediately estimated the glucose concentration in the blood using a glycated hemoglobin meter (EASY-A1C, Korea) to measure Hemoglobin A1c (HbA1c, glycated hemoglobin).

\section{Plasma MDA}

Plasma MDA was devised by Satoh and two Lipid Peroxidation (MDA) Assay kit (MAK085, Sigma-Aldrich, Canada, K739-100/BioVison, San Francisco, U.S.A) used (Satoh, 1978). In this method, MDA (malondialdehyde) and TBA (thiobarbituric acid), which are lipid oxidation reactants, react with spectrophotometry to cause a color development reaction to pink. After butanol extraction, peroxide lipids are measured by comparing them with standard curves at a wavelength of $532 \mathrm{~nm}$ using a spectrophotometer.

\section{Real-Time polymerase chain reaction (PCR)}

Total RNA was extracted from the pancreas using a kit (Bioneer, Daejeon, Korea), and total RNA was synthesized using AccuPower CycloScript RT Premix (Bioneer, Daejeon, Korea). Real-Time PCR was carried out after designing the primers of IR (Insulin Receptor), IRS1 (Insulin receptor substrate 1), Pl3K (Phosphoinositide 3-kinase), and Akt at $95^{\circ} \mathrm{C}$.

Akt protein is an important protein in the signaling process of insulin and can confirm the effect of improving insulin resistance by analyzing the degree of phosphorylation. Akt is extracted from liver tissue using a homogenizer, quantified through Bradford assay, and electrophoresis using $10 \%$ sodium dodecyl sulfate-polyacrylamide gel (SDS-PAGE). The protein of polyacrylamide was transferred to a polyvinylidene fluoride (PVDF) membrane. After membrane blocking, wash the remaining material with TBS-T. First, tAkt antibodies and pAkt antibodies are used, and secondary antibodies are used HRP-conjugated antibodies to confirm expression.

\section{Statistical analysis}

The mean and standard deviation ( \pm SD) were shown for each group, and the statistics were post-analysis through the T3 method of LSD and Dunnett using SPSS. The significance level was judged to be significant when $p<0.05$ (Niu et al., 2020). 


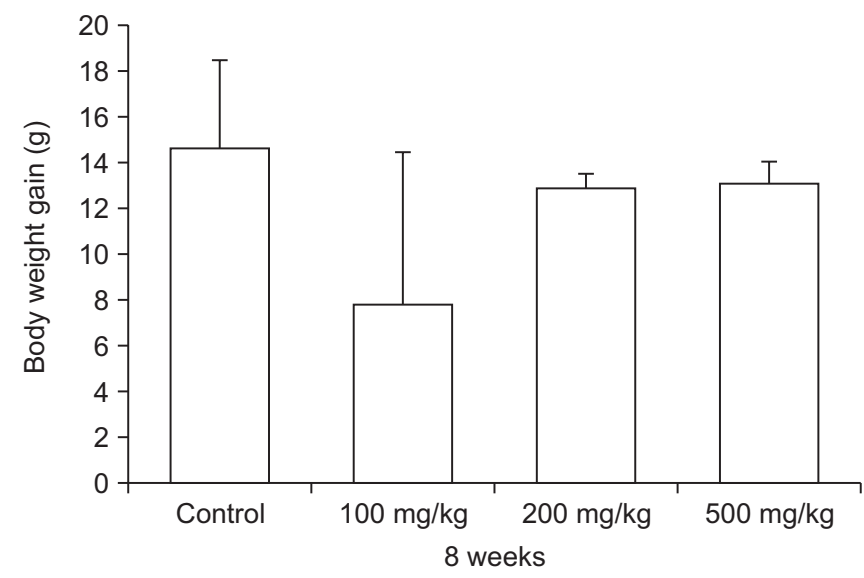

Fig. 1. Body weight gain of the mouse for 8 weeks. Values represent mean $\pm S D(n=5 \pm 2)$. No statistically significant weight difference between the control group.

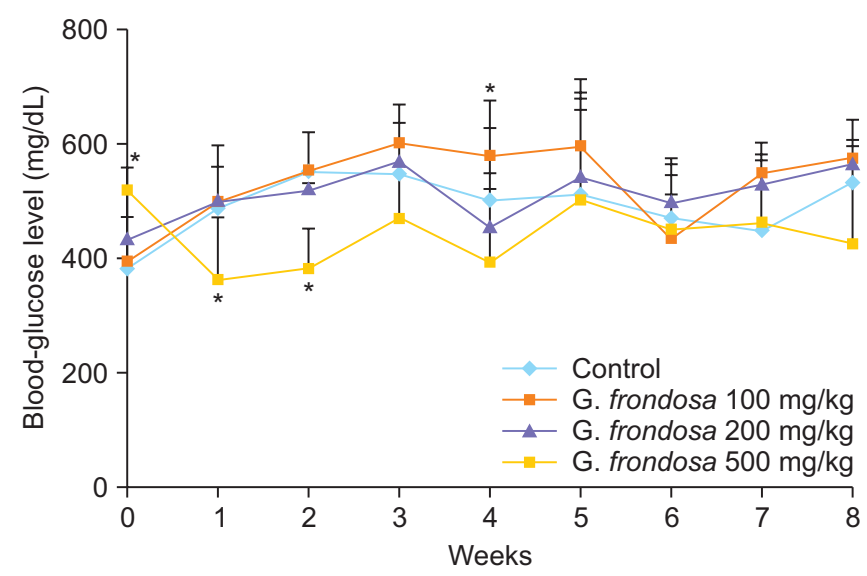

Fig. 2. $\mathrm{db} / \mathrm{db}$ mouse blood glucose level for 8 weeks. Blue is a control group, orange, purple, and yellow are $100 \mathrm{mg} / \mathrm{kg}, 200$ $\mathrm{mg} / \mathrm{kg}$, and $500 \mathrm{mg} / \mathrm{kg}$. The control group did not contain $G$. frondosa, and blood was taken from the tail vein once a week. $100 \mathrm{mg} / \mathrm{kg}, 200 \mathrm{mg} / \mathrm{kg}, 500 \mathrm{mg} / \mathrm{kg}$ compared with control, LSD, ${ }^{*} p<0.05$. Values represent mean \pm SD $(n=5 \pm 2)$.

\section{RESULTS}

\section{Body weight}

The effects of $G$. frondosa extract containing feed for 8 weeks on the weight of the mouse is appeared on the Fig. 1. For convenience, the group fed the feed that did not process $G$. frondosa referred to as control. All showed a trend of weight gain, but no statistically significant weight difference was observed between the control group. Both the control group and the induced group showed a tendency to gain weight. However, compared to the control group, the weight gain was relatively low in all induced groups. In the experimental group, it was also confirmed

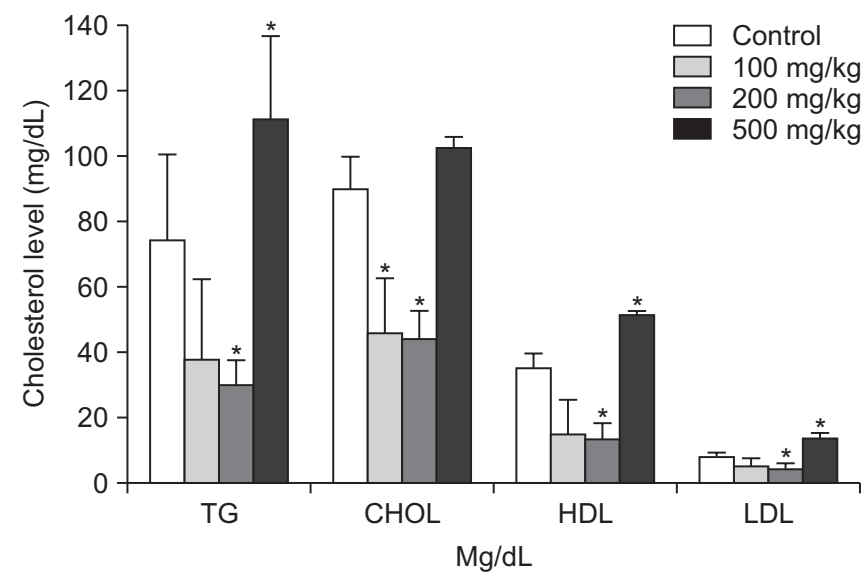

Fig. 3. Biochemical Lipid Test in $\mathrm{db} / \mathrm{db}$ mouse. In the graph, the $X$ axis is expressed in the order of triglycerides (TG), cholesterol $(\mathrm{CHOL})$, high density lipoprotein ( $\mathrm{HDL})$, and low density lipoprotein $(\mathrm{LDL})$, respectively, and the units are $\mathrm{mg} / \mathrm{dL}$. The order of the groups is control, $100 \mathrm{mg} / \mathrm{kg} \mathrm{G}$. frondosa, $200 \mathrm{mg} /$ $\mathrm{kg} \mathrm{G}$. frondosa, $500 \mathrm{mg} / \mathrm{kg} \mathrm{G}$. frondosa from the left. $200 \mathrm{mg} /$ $\mathrm{kg}$ and $500 \mathrm{mg} / \mathrm{kg}$ fed groups have significant difference compared with control, LSD, Dunnette's T3, * $p<0.05$.

that $100 \mathrm{mg} / \mathrm{kg}$ treated group had the lowest weight gain. In the control group, the weight gain was the highest, it can be seen $G$. frondosa affects body weight.

\section{Effects of $G$. frondosa on blood sugar level}

The results of measuring blood sugar by collecting blood from the tail vein of the $\mathrm{db} / \mathrm{db}$ mouse every week (Fig. 2). The group at the highest $500 \mathrm{mg} / \mathrm{kg}$ concentration recorded generally lower blood sugar levels than the other group. In addition, the treatment group generally shows a level of blood sugar level like that of the control group. Until the 5 weeks, the higher the concentration of $G$. frondosa mixed in feed, the lower the blood sugar. In Group B, it was observed that the level dropped sharply in Week 6. It is predicted that the average blood sugar level was lowered due to inflammation of the tail during collecting blood.

\section{Biochemical test of lipid}

Blood lipid levels were generally low in the $\mathrm{db} / \mathrm{db}$ mouse groups fed G. frondosa at the concentration of $100 \mathrm{mg} /$ $\mathrm{kg}$ or $200 \mathrm{mg} / \mathrm{kg}$, but blood lipid levels like those of the control group were shown in the $\mathrm{db} / \mathrm{db}$ mouse group fed G. frondosa at the concentration of $500 \mathrm{mg} / \mathrm{kg}$ (Fig. 3). Groups B $(100 \mathrm{mg} / \mathrm{kg})$ and group C $(200 \mathrm{mg} / \mathrm{kg})$ showed lower levels than the control group, and $\mathrm{B}$ presented slightly higher values than $C$. It is characterized by the 
Yun and Kim. G. frondosa improve blood lipids metabolism

Table 2. Hemoglobin A1c (HbA1c) level for each group

\begin{tabular}{ccccc}
\hline & Group A (control) & Group B $(100 \mathrm{mg} / \mathrm{kg})$ & Group C (200 mg/kg) & Group D (500 mg/kg) \\
\hline $\mathrm{HbA1c}(\%)$ & 9.9 & $9.27 \pm 1.02$ & 10 & $7.80 \pm 0.10$ \\
\hline
\end{tabular}

Each data was expressed in percentage, and for convenience, it was named as A, B, C, and D groups in the order of control, $100 \mathrm{mg} / \mathrm{kg}, 200 \mathrm{mg} / \mathrm{kg}, 500$ $\mathrm{mg} / \mathrm{kg}$ about $\mathrm{G}$. frondosa. Values represent mean $\pm \mathrm{SD}(n=5 \pm 2)$. Groups $A, C$ are statistically processed as data for one individual, and the standard deviation appears to be zero. There was no significant difference, Dunnette's T3, ${ }^{*} p<0.05$.

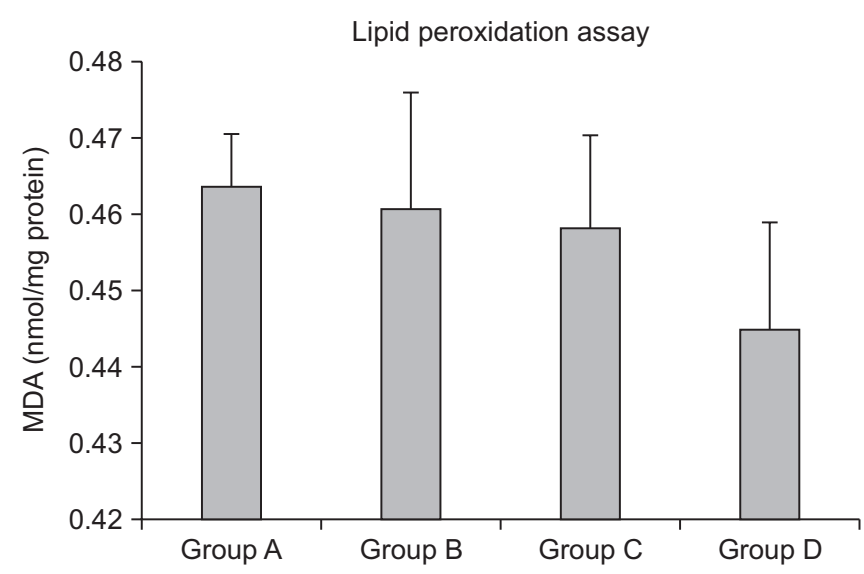

Fig. 4. Measurement of MDA in plasma from $\mathrm{db} / \mathrm{db}$ mouse. The unit of each data was $\mathrm{nmol} / \mathrm{mg}$, and the result wase calculated rounded up to the second digit after the decimal point. Data represent means \pm SD form $5 \pm 2$. There was no significant $(p<0.05)$ differences. Group A (control), Group B (G. frondosa $100 \mathrm{mg} / \mathrm{kg}$ ), Group C (G. frondosa $200 \mathrm{mg} / \mathrm{kg}$ ), and Group D (G. frondosa 500 $\mathrm{mg} / \mathrm{kg}$ ). MDA assay was performed using Lipid Peroxidation (MDA) Assay kit (MAK085, Sigma-Aldrich, Canada, K739-100/BioVison, San Francisco, U.S.A).

highest level on triglycerides (TG), cholesterol (CHOL), high density lipoprotein (HDL), and low-density lipoprotein (LDL) in the group D (G. frondosa $500 \mathrm{mg} / \mathrm{kg}$ ).

\section{Glucose level test with hemoglobin A1c}

Glycated hemoglobin (HbA1c) is one of the most commonly used indicators of blood glucose and can predict blood glucose levels in the long term. Glucose level was the lowest in the group D fed at the highest concentration $(500 \mathrm{mg} / \mathrm{kg})$ in Table 2. Except for group D, the two groups $\mathrm{B}$ and $\mathrm{C}$ show similar values to the control group.

\section{Lipid peroxidation (MDA) assay}

Peroxide lipids are lipid degradation reactions that occur as a result of oxidative damage, and are sometimes used as markers for oxidative stress. In this study, MDA assay was conducted to measure oxidative stress in the mouse. As a result of the measurement, $0.4637 \mathrm{nmol} / \mathrm{mg}$ values were shown in the group A (control), $0.4607 \mathrm{nmol} /$

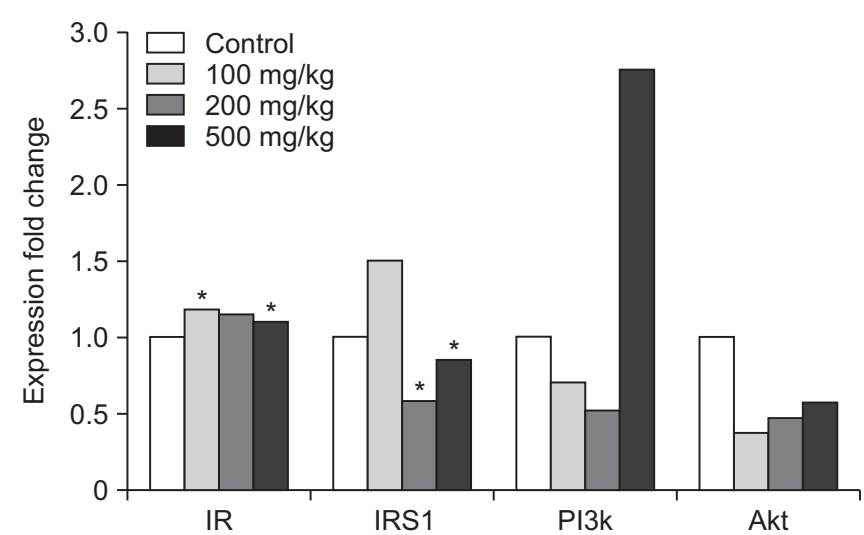

Fig. 5. Real-Time PCR results for IR, IRS1, PI3K, Akt expression relative to GAPDH mRNA in pancreas and liver of $\mathrm{db} / \mathrm{db}$ mouse. Each figure is expressed as a relative value. $\mathrm{db} / \mathrm{db}$ mouse fed G. frondosa $100 \mathrm{mg} / \mathrm{kg}$ and $500 \mathrm{mg} / \mathrm{kg}$ were significant different from control in IR expression, Dunnette's T3, * $p<0.05 .200$ $\mathrm{mg} / \mathrm{kg}$ and $500 \mathrm{mg} / \mathrm{kg}$ were significant different from control in IRS1 expression, Dunnette's T3, * $p<0.05$.

mg in Group B (G. frondosa $100 \mathrm{mg} / \mathrm{kg}$ ), $0.4584 \mathrm{nmol} / \mathrm{mg}$ in Group C (G. frondosa $200 \mathrm{mg} / \mathrm{kg}$ ), and 0.4449 in Group D (G. frondosa $500 \mathrm{mg} / \mathrm{kg}$ ). The value for lipid peroxidation was low in the order of groups A, B, C, and D. In particular, in Group D, as can be seen from the Fig. 4, lower values identified different from other groups.

\section{Analysis of mRNA expression levels of IR, IRS1, PI3k,} Akt

When Real-Time PCR was performed using the pancreas stored in RNA later, the expression levels of IR, IRS1, PI3K, and Akt were compared with those of GAPDH, a housekeeping gene (Fig. 5). Fig. 5 appeared analysis of messenger RNA expression of the IR, IRS1, Pl3K, Akt genes. When compared with the control group, there were significant differences in the levels of IR expression in fed G. frondosa $100 \mathrm{mg} / \mathrm{kg}$ and $\mathrm{G}$. frondosa $500 \mathrm{mg} / \mathrm{kg}$. In addition, there were significant differences in the levels of IRS1 expression in $200 \mathrm{mg} / \mathrm{kg}$ and $500 \mathrm{mg} / \mathrm{kg}$ of $\mathrm{G}$. frondosa. 


\section{DISCUSSION}

Public concerns about diabetes prevention and treatment have increased, finding natural products that can help alleviate diabetes has become more important (Kang et al., 2010). In this study, the above written results were synthesized to check the effect of $G$. frondosa according to its concentration in BKS.Cg-+Lepr ${ }^{\mathrm{db}} /+\mathrm{Lepr}^{\mathrm{db}} / \mathrm{OlaHsd}$ mice. At the same time, we tried to find out how G. frondosa works in diabetic disease mouse model.

We performed the biochemical lipid test and the MDA test. Not only was the blood sugar measurement conducted, but also the lipid metabolism was investigated. It is important to figure out how $G$. frondosa affect lipid metabolism. Former studies mainly focused on blood sugar, but this study conscious lipid metabolism (Park et al., 2007).

Also, animal experiments are conducted only on male rodents in most studies. Previous studies have mainly confirmed the effect of $G$. frondosa on male mouse (Xiao et al., 2015; Chen et al., 2019). However, in this study, we proceeded with female. We thought it was necessary to understand the pattern of occurrence of diseases according to gender differences. So, the study focused on female mouse model. It is not limited to one gender, but we think it is more efficient to compare the two genders.

We assume that there is a difference between male and female due to physiological stress. As a result, as stress changes, differences according to gender may appear. Except for reproductive behavior, sex hormone-dependent cancer, and reproductive traits, most disease patterns are different between male and female (Mauvais-Jarvis et al., 2017).

Diabetes mellitus is a chronic disease that spreads around the world. According to the International Diabetes Federation (IDF), about 382 million people worldwide suffered from diabetes in 2013 (Palamenghi et al., 2020).

Diabetes is characterized by an increase in blood sugar levels and a gradual decrease in blood insulin (Kim et al., 2010). In addition, diabetes causes various fatal complications. Therefore, heart diseases can be said to be a representative complication in diabetic patients. Cardiovascular disease is a major cause of morbidity and mortality among diabetic patients, and it is important to choose anti-diabetes that can reduce the risk of cardiovascular disease (Kumar et al., 2016). Atherosclerosis, which causes heart diseases, is caused by various causes, and dyslipidemia is the most important risk factor for heart diseases. Regulatory abnormalities in lipid metabolism often occur in diabetic patients. Diabetes is associated with myocardial glucose intake disorder, thus increasing dependence on fatty acids as a source of adenosine triphosphate (ATP) in the heart. It is further caused by dyslipidemia and the importance of lipids in the development of diabetic cardiomyopathy is particularly important (Ritchie et al., 2017).

Referring to the weight gain for a total of 8 weeks from the initial weight (7 weeks old), both the control group and the experimental group showed a trend of increasing weight. There was no statistically significant difference in weight, but the growth rate was the highest in the control group. On low concentrations $(100 \mathrm{mg} / \mathrm{kg})$, the weight gain rate was particularly low. The lower the concentration, the lower the weight gain rate. In other words, the higher the concentration, the less weight loss it is. Also, compared to the control group, $100 \mathrm{mg} / \mathrm{kg}$ group showed much less weight gain. Rapid weight loss is known as one of the disease symptoms in normal-weight type 2 diabetes patients known as insulin-independent diabetes (Park et al., 2001). Previous studies have reported that the prognosis of underweight type 2 diabetes patients is poor. It has also been reported that it is still unclear whether weight loss can reduce the risk of death (Costanzo et al., 2015). Furthermore, normal-weight people diagnosed with type 2 diabetes are more than twice as likely to die from heart disease and other causes as overweight patients (Carnethon et al., 2012). Type 2 diabetes causes weight loss (Yeo et al., 2010). This can be taken as an improvement. Based on this, we can assume that the negative aspect is that weight loss is evident at low concentrations.

Moreover, the higher the concentration of $G$. frondosa, the lower the glucose level. In week 6, Group B (100 mg/ $\mathrm{kg}$ of $G$. fronodosa) suddenly appeared a low average blood sugar level. It is predicted that the average blood sugar level decreased due to inflammation of the tail during the glucose level check process.

Lipid biochemical tests were performed for blood triglycerides, total cholesterol, HDL cholesterol, and LDL cholesterol to examine abnormalities in lipid metabolism due to diabetes. $G$. frondosa generally have been known to be effective in treating cholesterol and obesity (Park, 2008). When compared with the control group, the blood 
lipid levels were generally lower in the groups fed $100 \mathrm{mg} /$ $\mathrm{kg}$ or $200 \mathrm{mg} / \mathrm{kg}$ of $\mathrm{G}$. frondosa. Though, blood lipid levels in $\mathrm{db} / \mathrm{db}$ mouse group fed $G$. frondosa at the concentration of $500 \mathrm{mg} / \mathrm{kg}$ were higher than control group. The highest value was recorded not only in TG, CHOL, and HDL but also in LDL. Rather, the group that fed at a high concentration $(500 \mathrm{mg} / \mathrm{kg}$ ) showed higher figure than the control group and other groups. In previous studies, it has been reported that the high dose of $G$. frondosa was administered to female mouse, resulting in a slight weight gain (Oh et al., 2010). Therefore, G. frondosa showed favorable effects for lipid improvement at concentrations not higher than $200 \mathrm{mg} / \mathrm{kg}$.

Glycated hemoglobin is one of the most commonly used indicators of blood glucose, and HbA1c, a part of hemoglobin in red blood cells, slowly binds to glucose and nonenzymatic binding during survival. Therefore, the degree of glycation of HbA1c causes blood glucose concentration to be predicted (Sherwani et al., 2016). Compared to glucose in the average blood, $7-8 \%$ corresponds to $150-180$ $\mathrm{mg} / \mathrm{dL}$ and $8.3-10 \mathrm{mmol} / \mathrm{L}$, which is slightly higher. 8.5$10 \%$ is a high level of $180-240 \mathrm{mg} / \mathrm{dL}$ and $10-13.3 \mathrm{mmol} /$ $\mathrm{L}$ for average blood glucose. In addition, more than $10.5 \%$ of $\mathrm{HbA} 1 \mathrm{c}$ has an average blood glucose level of $240 \mathrm{mg} /$ $\mathrm{dL}$ and $13.3 \mathrm{mmol} / \mathrm{L}$ to $14 \mathrm{mmol} / \mathrm{L}$, and is known to be very high (Cagliero et al., 1999).

Group A (control), B (100 mg/kg), and C (200 mg/kg) all exhibited high levels of glucose in the blood. In contrast, the glycated hemoglobin in the group that treated 500 $\mathrm{mg} / \mathrm{kg}$ of $\mathrm{G}$. frondosa was $7.8 \%$, which was about $25 \%$ lower than that of other groups. Therefore, the degree of glycation of $\mathrm{HbA} 1 \mathrm{c}$ was low in mice that administered high concentrations of $G$. frondosa.

Lipid peroxide is a product of lipid lowering reaction occurring as a result of oxidative damage, and is also used as a marker of oxidative stress. The induction of oxidative stress is cause an organ malformation is mainly responsible (An et al., 2021). Lipid peroxidation assay showed no significant difference in any of the experimental groups.

Type 2 diabetes refers to the condition under which insulin signaling is not properly carried out due to insulin resistance. Recently, type 2 diabetes accounts for more than $90 \%$ of diabetic patients (Chatterjee et al., 2017) Due to the decrease in insulin sensitivity, insulin cannot bind to the insulin receptors even when insulin is expressed so that the action of insulin does not occur and high blood sugar levels are maintained. The glucose remaining in blood stimulates the pancreas to increase insulin secretion so that more insulin is secreted into blood to cause even hyperinsulinemia. Insulin resistance can be identified through changes in the expression of proteins related to insulin signaling. In the above experiment, the mRNA expression levels of IR, IRS1, PI3K, and Akt, which are in the insulin signaling pathway were compared with those of GAPDH through Real-Time PCR. According to the results, in the case of the female groups, the experimental groups showed significantly higher IR expression levels compared to the control group. IRS1 is a receptor molecule in which tyrosine residues are phosphorylated in response to insulin, IGF-1, cytokine, etc. It serves to an important role in insulin signaling. IRS1 is activated by phosphorylation of tyrosine to form a signal carrier such as PI3K (Gual et al., 2005). Insulin receptor activated by insulin promote intracellular glucose absorption through the PI3k pathway (Müssig et al., 2005).

In this study, $G$. frondosa extract improved blood lipid levels and, in the case of feed treated with $G$. frondosa at a high concentration, effects to improve diabetic diseases could be identified through blood lipid biochemical tests and Real-Time PCR evaluation.

However, with regard to insulin signaling, no significant difference in insulin resistance appeared. Therefore, in future studies, to investigate blood sugar level lowering mechanisms, additional experiments seem to be necessary on alpha glucosidase, which temporarily lowers blood sugar by interfering with the digestion of carbohydrates after a meal, or the mechanism of the occurrence of insulin resistance against the promotion of insulin secretion. The experiment was conducted with female. The results are significant.

In this regard, further research is needed on what mechanism $G$. frondosa have and influence according to gender. No significant difference was found in the MDA test. Additional experiments and investigations are required for this. In addition, it seems like that the components of the $G$. frondosa extract should be fractionalized to conduct concrete experiments to figure out which components show antidiabetic effects. G. frondosa derived from natural materials are supposed to have the potential to resolve the side effects of commercially available diabetes treatments. 


\section{CONCLUSION}

To find out the effect of Grifola frondosa (G. frondosa) the study was conducted in diabetic disease model mouse (BKS.Cg-+Lepr ${ }^{\mathrm{db}} /+$ Lepr $^{\mathrm{db}} / \mathrm{OlaHsd}$ ). Lipid metabolism was investigated, and changes were observed after 8 weeks of oral administration. There is no clear treatment for diabetes yet, so it is necessary to identify and come up with a solution. G. frondosa revealed the effect of improving blood lipids in the diabetes model. Therefore, this study is considered to suggest the possibility for the application of $G$. frondosa in diabetes.

Author Contributions: Conceptualization, S.B.Y. and D.Y.K.; investigation, S.B.Y. and D.Y.K.; writing-original draft, S.B.Y. and D.Y.K.; writing-review \& editing, D.Y.K.

Funding: This research was supported by the Basic Science Research Program through the National Research Foundation of Korea (NRF) funded by the Ministry of Education (Project No. 2017R1A2B1010690).

Ethical Approval: Not applicable.

Consent to Participate: Not applicable.

Consent to Publish: Not applicable.

Availability of Data and Materials: Not applicable.

Acknowledgements: This study was supported by the Basic Science Research Program through the National Research Foundation of Korea (NRF) funded by the Ministry of Education (Project No. 2017R1A2B1010690).

Conflicts of Interest: No potential conflict of interest relevant to this article was reported.

\section{REFERENCES}

An G, Park H, Song G, Lim W. 2021. Developmental toxicity of dimethachlor during zebrafish embryogenesis mediated by apoptosis and oxidative stress. J. Anim. Reprod. Biotechnol. 36:2-8.

Cagliero E, Levina EV, Nathan DM. 1999. Immediate feedback of HbAlc levels improves glycemic control in type 1 and insulin-treated type 2 diabetic patients. Diabetes Care
22:1785-1789.

Carnethon MR, De Chavez PJ, Biggs ML, Lewis CE, Pankow JS, Bertoni AG, Golden SH, Liu K, Mukamal KJ, CampbellJenkins B, Dyer AR. 2012. Association of weight status with mortality in adults with incident diabetes. JAMA 308:581590.

Chatterjee S, Khunti K, Davies MJ. 2017. Type 2 diabetes. Lancet 389:2239-2251.

Chen Y, Liu D, Wang D, Lai S, Zhong R, Liu Y, Yang C, Liu B, Sarker MR, Zhao C. 2019. Hypoglycemic activity and gut microbiota regulation of a novel polysaccharide from Grifola frondosa in type 2 diabetic mice. Food Chem. Toxicol. 126:295-302.

Cho J, Uh K, Ryu J, Fang X, Bang S, Lee K. 2020. Development of PCR based approach to detect potential mosaicism in porcine embryos. J. Anim. Reprod. Biotechnol. 35:323-328.

Costanzo P, Cleland JG, Pellicori P, Clark AL, Hepburn D, Kilpatrick ES, Perrone-Filardi P, Zhang J, Atkin SL. 2015. The obesity paradox in type 2 diabetes mellitus: relationship of body mass index to prognosis: a cohort study. Ann. Intern. Med. 162:610-618.

Gual P, Le Marchand-Brustel Y, Tanti JF. 2005. Positive and negative regulation of insulin signaling through IRS-1 phosphorylation. Biochimie 87:99-109.

International Diabetes Federation. 2015. IDF Diabetes Atlas. 7th ed, International Diabetes Federation, Brussels, pp. 1014.

Joung H, Kim C, Lee Y, Kim S, Do MS. 2017. Anti-diabetic and anti-inflammatory effects of purple corn extract in high-fat diet induced obesity mice. Korean J. Food Nutr. 30:696-702.

Kanasaki K and Koya D. 2011. Biology of obesity: lessons from animal models of obesity. J. Biomed. Biotechnol. 2011:197636.

Kang MH and Choi MK. 2010. Antidiabetic activities analysis by oral glucose tolerance test in rats. Reprod. Dev. Biol. 34:305308.

Kim JH, Lee Y, Lee S, Suzuki T, Lee SK, Kang T, Hong Y. 2010. Effect of streptozotocin-induced diabetes on bone and heart development in juvenile rats. Reprod. Dev. Biol. 34:81-88.

Kumar R, Kerins DM, Walther T. 2016. Cardiovascular safety of anti-diabetic drugs. Eur. Heart J. Cardiovasc. Pharmacother. 2:32-43.

Ma X, Zhou F, Chen Y, Zhang Y, Hou L, Cao X, Wang C. 2014. A polysaccharide from Grifola frondosa relieves insulin resistance of HepG2 cell by Akt-GSK-3 pathway. Glycoconj. J. 31:355-363.

Matsuura H, Asakawa C, Kurimoto M, Mizutani J. 2002. Alphaglucosidase inhibitor from the seeds of balsam pear (Momordica charantia) and the fruit bodies of Grifola frondosa. Biosci. Biotechnol. Biochem. 66:1576-1578.

Mauvais-Jarvis F, Arnold AP, Reue K. 2017. A guide for the design of pre-clinical studies on sex differences in metabolism. Cell Metab. 25:1216-1230.

Müssig K, Staiger H, Fiedler H, Moeschel K, Beck A, Kellerer M, Häring HU. 2005. Shp2 is required for protein kinase C- 
dependent phosphorylation of serine 307 in insulin receptor substrate-1. J. Biol. Chem. 280:32693-32699.

Nagel AK, Ahmed-Sarwar N, Werner PM, Cipriano GC, Van Manen RP, Brown JE. 2016. Dipeptidyl peptidase-4 inhibitor-associated pancreatic carcinoma: a review of the FAERS database. Ann. Pharmacother. 50:27-31.

Niu YJ, Zhou D, Zhou W, Nie ZW, Kim JY, Oh Y, Lee SR, Cui XS. 2020. Nitric oxide-induced protein S-nitrosylation causes mitochondrial dysfunction and accelerates post-ovulatory aging of oocytes in cattle. J. Anim. Reprod. Biotechnol. 35:102-111.

Oh YJ, Park KJ, Ha HC, Kim HS. 2010. Acute toxicity evaluation of maitake mushroom extract and the mixture of maitake and white jelly mushroom extract. J. Mushroom Sci. Prod. 8:91-95.

Palamenghi L, Carlucci MM, Graffigna G. 2020. Measuring the quality of life in diabetic patients: a scoping review. J. Diabetes Res. 2020:541929.

Park HJ, Lee IO, Kim SH. 2001. Past and present obesity, parameters of body fat and blood pressure in Korean patients with non-insulin dependent diabetes mellitus (NIDDM). J. Korean Acad. Nurs. 31:1034-1043.

Park KJ, Oh YJ, Lee SY, Kim HS, Ha HC. 2007. Anti-diabetic effect of crude polysaccharides from Grifola frondosa in KKAy diabetic mouse and 3T3-L1 adipocyte. Korean J. Food Sci. Technol. 39:330-335.

Park KM. 2008. Industrialization of mushroom functional substances. J. Mushroom Sci. Prod. 6:1-12.

Reid TS. 2013. Practical use of glucagon-like peptide-1 receptor agonist therapy in primary care. Clin. Diabetes 31:148-157.

Ritchie RH, Zerenturk EJ, Prakoso D, Calkin AC. 2017. Lipid metabolism and its implications for type 1 diabetes-associated cardiomyopathy. J. Mol. Endocrinol. 58:R225-R240.

Satoh K. 1978. Serum lipid peroxide in cerebrovascular disorders determined by a new colorimetric method. Clin. Chim. Acta 90:37-43.

Sherwani SI, Khan HA, Ekhzaimy A, Masood A, Sakharkar MK. 2016. Significance of $\mathrm{HbAlc}$ test in diagnosis and prognosis of diabetic patients. Biomark. Insights 11:95-104.

Soares R, Meireles M, Rocha A, Pirraco A, Obiol D, Alonso E, Joos G, Balogh G. 2011. Maitake (D fraction) mushroom extract induces apoptosis in breast cancer cells by BAK-1 gene activation. J. Med. Food 14:563-572.

Suzuki I, Itani T, Ohno N, Oikawa S, Sato K, Miyazaki T, Yadomae T. 1984. Antitumor activity of a polysaccharide fraction extracted from cultured fruiting bodies of Grifola frondosa. J. Pharmacobiodyn. 7:492-500.

Xiao C, Wu Q, Tan J, Cai W, Yang X, Zhang J. 2011. Inhibitory effects on $\alpha$-glucosidase and hypoglycemic effects of the crude polysaccharides isolated from 11 edible fungi. J. Med. Plant. Res. 5:6963-6967.

Xiao C, Wu Q, Xie Y, Zhang J, Tan J. 2015. Hypoglycemic effects of Grifola frondosa (Maitake) polysaccharides F2 and F3 through improvement of insulin resistance in diabetic rats. Food Funct. 6:3567-3575.

Yang W, Cai X, Han X, Ji L. 2016. DPP-4 inhibitors and risk of infections: a meta-analysis of randomized controlled trials. Diabetes Metab. Res. Rev. 32:391-404.

Yeo MH, Seo JG, Chung MJ, Lee HG. 2010. Effect of lactic acid bacteria on the regulation of blood glucose level in streptozotocin-induced diabetic rats. Reprod. Dev. Biol. 34:299304. 